\title{
COMPOSIÇÃO FLORÍSTICA E ESTRUTURA DE UM TRECHO DE FLORESTA OMBRÓFILA DENSA ATLÂNTICA COM USO PRETÉRITO DE PRODUÇÃO DE BANANA, NO PARQUE ESTADUAL DA PEDRA BRANCA, RIO DE JANEIRO, RJ'
}

\author{
Alexandro Solórzano², Rejan Rodrigues Guedes-Bruni ${ }^{3}$ e Rogério Ribeiro de Oliveira ${ }^{4}$
}

\begin{abstract}
RESUMO - Este estudo teve como objetivos caracterizar florística e estruturalmente um trecho de Floresta Ombrófila Densa Submontana urbana e avaliar os fatores que contribuíram para a regeneração, a partir do último uso do solo para produção de banana, há 50 anos. Para a amostragem da área foram implantadas 25 parcelas de $100 \mathrm{~m}^{2}$, totalizando 0,25 ha. O critério de inclusão adotado foi diâmetro à altura do peito (DAP) $\geq 5 \mathrm{~cm}$. Foram amostrados 311 indivíduos de 92 espécies, 67 gêneros e 31 famílias. A área basal total foi de $34,18 \mathrm{~m}^{2} / \mathrm{ha}$, enquanto a densidade, de 1.244 ind./ha. As espécies mais importantes na comunidade, representando $42 \%$ do valor de importância (VI) da área, foram: Aiouea saligna Meisn., Tachigali paratyensis (Vell.) H.C. Lima, Ficus insipida Willd., Bathysa gymonocarpa K. Schum, Chrysophyllum flexuosum Mart., Piptadenia gonoacantha (Mart.) J.F. Macbr., Piper rivinoides Kunth., Hyeronima alchorneoides Allemão, Miconia cinnamomifolia (DC.) Naudin e Guarea guidonia (L.) Sleumer. O elevado valor do Índice de diversidade de Shannon (H'= 4,13 nats/ind.), bem como o de equabilidade $(\mathrm{J}=0,91)$, compara-se aos valores referenciados para florestas conservadas e inventariadas no Sudeste brasileiro. A floresta amostrada encontra-se em processo de regeneração e representa um estágio intermediário de sucessão. O cultivo da banana, após seu abandono, permitiu a entrada de espécies com estratégias de estabelecimento e propagação em condições de pouca luminosidade. A presença de uma árvore remanescente, do gênero Ficus, está relacionada a uma crença popular que acabou influenciando a estrutura da vegetação. Dessa forma, as espécies amostradas neste estudo refletiram o uso do solo passado e a cultura local.
\end{abstract}

Palavras-chave: Estrutura, Mata Atlântica, História de uso do solo e Plantação de banana.

\section{FLOWER COMPOSITION AND STRUCTURE OF AN ATLANTIC RAIN FOREST TRACT, WITH LAND USE HISTORY OF BANANA PLANTATION AT THE PEDRA BRANCA STATE PARK, RIO DE JANEIRO, BRAZIL}

\begin{abstract}
The objective of this study was to determine the structure and composition of an Atlantic Rain Forest tract with a land use history of banana plantation 50 year ago and evaluate the factors that influence its regeneration. Individual trees and shrubs with diameter at breast height $(\mathrm{dbh}) \geq 5 \mathrm{~cm}$ were sampled within 25 plots of $10 \times 10 \mathrm{~m}$ for a total sample size of $0.25 \mathrm{ha}$. We found 311 stems distributed across 92 species, 67 genera and 31 families, with a basal area of $34.18 \mathrm{~m}^{2} / \mathrm{ha}$ and a density of 1,244 ind./ha. The ten species with the highest importance value(IV) were the following: Aiouea saligna Meisn., Tachigali paratyensis(Vell.)H.C. Lima, Ficus insipida Willd., Bathysa gymonocarpa K. Schum, Chrysophyllum flexuosum Mart., Piptadenia gonoacantha (Mart.) J.F. Macbr, Piper rivinoides Kunth., Hyeronima alchorneoides Allemão, Miconia cinnamomifolia (DC.) Naudin and Guarea guidonia $(L$.) Sleumer. The high Shannon richness index and Pielou index $\left(H^{\prime}=4.13\right.$ nats/ind. and $\left.J^{\prime}=0.91\right)$, are close to those of preserved forest stands of AtlanticRain Forest, suggesting a good recovery process for this stand, representing an intermediary stage of successional dynamics. The abandonment of the banana plantation created an environment of heterogeneous light conditions, allowing for the entry of species with different establishment strategies. The presence of a remnant tree of the Ficus genus, is related to a popular belief that ended up influencing the vegetation structure. Thus, the species sampled in this study reflected the past land use and the local culture.
\end{abstract}

Keywords: Structure, Atlantic Rain Forest, Land use history and Banana plantation.

\footnotetext{
${ }^{1}$ Recebido em 27.08.2008 e aceito para publicação em 19.04.2012.

${ }^{2}$ Doutorado em Ecologia pela Universidade de Brasília, UNB, Brasil. Email: <alexandrosol@ gmail.com>.

${ }^{3}$ Instituto de Pesquisa Jardim Botânico do Rio de Janeiro, IP/JBRJ, Brasil. E-mail: <rbruni@ jbrj.gov.br>.

${ }^{4}$ Pontifícia Universidade Católica do Rio de Janeiro, PUC-Rio, Brasil. E-mail: <rro@geo.puc-rio.br>
} 


\section{INTRODUÇÃO}

As florestas secundárias vêm ocupando cada vez mais espaço na literatura científica, e sua compreensão tem subsidiado estudos relativos à recuperação de áreas alteradas. Mundialmente, estimase que $31 \%$ das florestas consideradas densas ("fechadas") são, na verdade, florestas secundárias (BROWN; LUGO, 1990). A despeito de sua importância para a conservação, bem como para a restauração de áreas degradadas, a definição do que realmente seja uma floresta secundária é matéria controversa. Destaca-se que florestas secundárias continuam a fornecer atributos para a restauração da qualidade do solo e da água, conservando componentes abióticos imprescindíveis à recuperação da paisagem (BROWN; LUGO, 1990).

Essas florestas têm destacada importância, principalmente nos biomas ameaçados, onde trechos pouco perturbados se encontram ilhados em meio à paisagem formada por um mosaico de florestas de diferentes idades, entrecortados por centros urbanos, pastos, plantações e outros tipos de uso do solo.

Atualmente, a Mata Atlântica encontra-se reduzida a menos de $8 \%$ de sua cobertura original (CONSERVATION INTERNATIONALDO BRASIL et al., 2000). No Estado do Rio de Janeiro, a Floresta Ombrófila Densa encontrava-se em maior proporção concentrada nas serras do Mar e da Mantiqueira, estando reduzida a $17 \%$ de seu território, dos quais apenas $30 \%$ circunscritos em unidades de conservação (SOS MATA ATLÂNTICA, 2002). Na cidade do Rio de Janeiro, os maiores fragmentos florestais distribuem-se nos principais maciços costeiros, a saber: Pedra Branca, Tijuca e Mendanha.

Na região Neotropical a prática de abandono de atividades agrícolas de pequena escala permite o rápido crescimento natural das florestas regenerantes (GUARIGUATA; OSTERAG, 2002). Assim, estas florestas secundárias constituem áreas com enorme potencial de manejo, mas que são, ainda, muito pouco estudadas.

Para que essa potencialidade possa ser adequadamente compreendida, são necessárias ações voltadas ao resgate histórico do uso do solo, ao conhecimento do processo de sucessão que se estabeleceu após sua exploração, ao monitoramento desses processos e à recuperação dos atributos florísticos e funcionais da floresta. Assim, este trabalho teve como objetivo caracterizar a composição florística, estrutura e diversidade arbórea de um trecho de floresta secundária de 50 anos, com uso pretérito para produção de banana. Com isso, teve-se o intuito de compreender como a história de uso do solo pode ter influenciado a dinâmica sucessional da floresta.

\section{MATERIAL E MÉTODOS}

\subsection{Caracterização da área de estudo}

A área de estudo localiza-se na Floresta do Camorim, situada no Maciço da Pedra Branca, Zona Oeste do Município do Rio de Janeiro, RJ (Figura 1). Atualmente, esse Maciço encontra-se circunscrito ao Parque Estadual da Pedra Branca, que tem uma área de 12.500 ha. Tratase de um Maciço Costeiro, com relevo acidentado, apresentando diversos afloramentos rochosos. Este trabalho foi realizado num trecho de Floresta Ombrófila Densa Submontana (IBGE, 1992), localizado no Morro da Mesa, utilizado para plantação de banana, atividade interrompida cerca de 50 anos atrás. A floresta estudada situava-se na bacia do rio Camorim (Figura 1), com 1.200 ha de extensão e um perímetro de $17 \mathrm{~km}$, tendo como principais tributários os rios São Gonçalo do Amarante e Caçambe.

O Maciço da Pedra Branca é composto basicamente por rochas cristalinas e cristalofilianas, granitos e principalmente o gnaisse facoidal, entrecortados por rochas básicas, como o diabásio (GALVÃO, 1957). Geologicamente, a região de Vargem Grande é constituída por granitos e gnaisse melanocrático, atravessados por pegmatitos e eruptivas básicas (NOGUEIRA, 1956).

O clima da região, segundo a classificação de Köpeppen, é do tipo Af, ou seja, clima tropical úmido sem estação seca, megatérmico. A altura pluviométrica média da região é de $1.187 \mathrm{~mm}$, ocorrendo deficiência hídrica episódica nos meses de julho a outubro. A temperatura média anual se encontra em torno de $26^{\circ} \mathrm{C}$ (RIO DE JANEIRO, 2000).

A área de estudo localiza-se na vertente sul do Maciço da Pedra Branca, mais especificamente sudoeste, voltado para o mar. Em outras palavras, esta vertente recebe mais umidade proveniente das chuvas orográficas do mar e das frentes frias. Ao mesmo tempo, recebe 


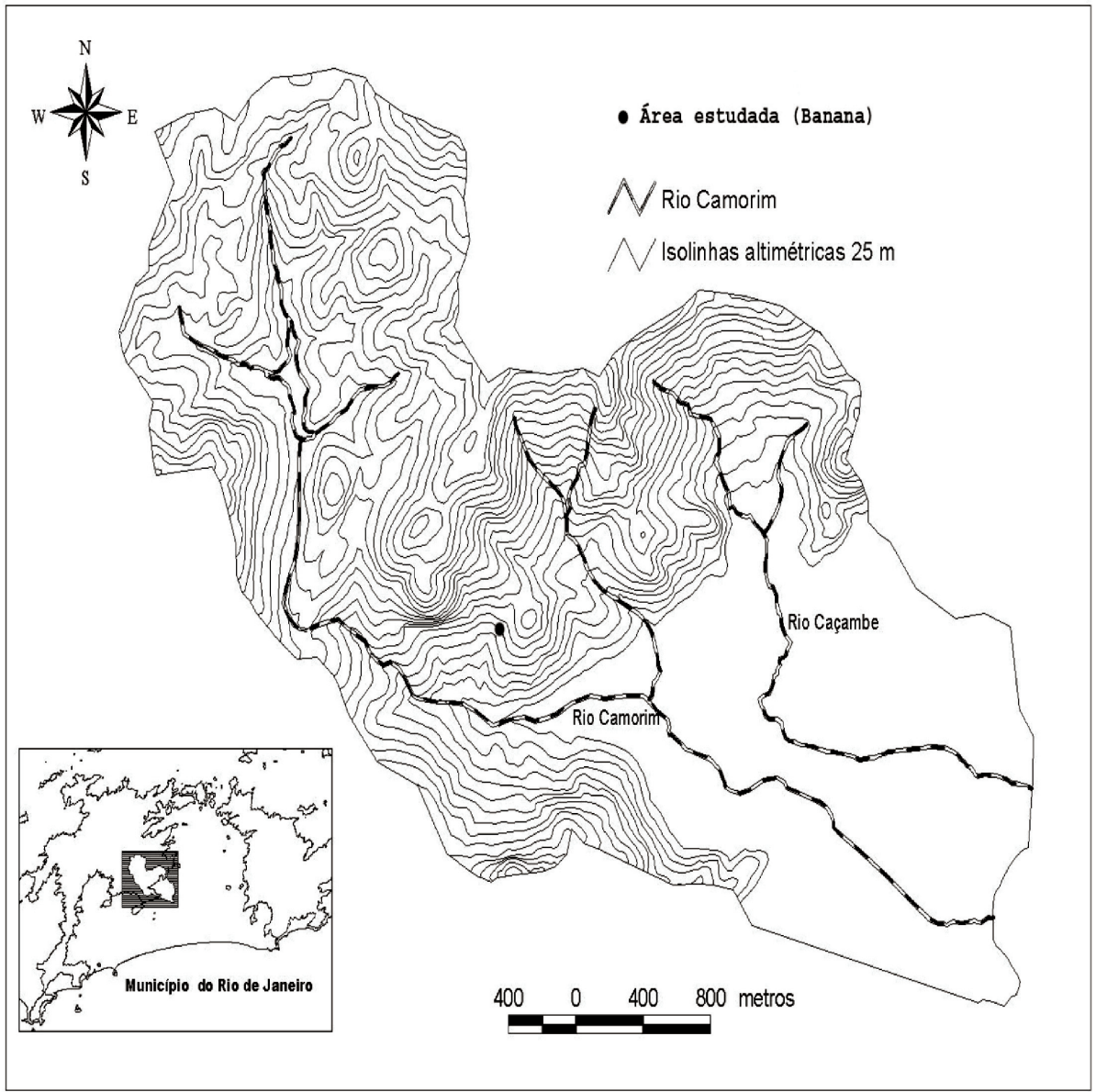

Figura 1 - Mapa topográfico da Bacia do rio Camorim, em destaque a área estudada. Figure 1 - Rio Camorin Basin Topographic map, with study area in evidence.

incidência menor de insolação do que a vertente norte, devido à posição no hemisfério sul.

A partir do século XX, as atividades agrícolas das encostas dessa região foram dominadas pela fruticultura, principalmente bananais, intercalados com a produção de pequena escala de lavoura branca, como chuchu, milho, aipim, batata-doce, jiló, maxixe e abóbora (NOGUEIRA, 1956; GALVÃO, 1957). Esse processo era precedido pelo aproveitamento da madeira da floresta, para lenha e carvão, sendo muitas vezes o carvoeiro também lavrador (NOGUEIRA, 1956). Portanto, na década de 1950 a produção de carvão e a plantação de banana eram atividades comuns no Camorim e que se complementavam uma à outra. Dessa forma, num mesmo lote ou terreno ocorria a sobreposição de usos da terra.
Em 1974, com a criação do Parque Estadual da Pedra Branca a utilização agrícola na região foi restringida, e as diferentes áreas encontram-se ocupadas, atualmente, por resquícios de bananais, dispersos pelas localidades de Grumari, Morro do Quilombo, Guaratiba etc., em caráter semiclandestino, cuja exploração é feita essencialmente de forma extrativista (FREITAS, 2003).

\subsection{Procedimentos metodológicos}

A escolha do local de estudo se deu a partir de entrevistas informais com moradores locais antigos, e a seleção da área amostral contou com o acompanhamento de um dos informantes para a confirmação exata do uso e a idade aproximada da floresta. 
Para a realização do inventário, empregou-se o método de parcelas (MUELLER-DOMBOIS; ELLENBERG, 1974). Foram demarcadas 25 parcelas, de $10 \times 10 \mathrm{~m}\left(100 \mathrm{~m}^{2}\right)$, dispostas sistematicamente, totalizando 0,25 ha. As parcelas foram estabelecidas com o auxílio de moradores tradicionais da localidade e implantadas no local onde, efetivamente, ocorreu o cultivo de banana; delimitadas de forma que tinha tamanho restrito, o que constituiu um caráter limitante para a demarcação das parcelas. O critério de inclusão adotado para os indivíduos amostrados foi $\mathrm{DAP} \geq 5 \mathrm{~cm}$ (diâmetro à altura do peito, 1,30 $\mathrm{m}$ do solo). Para os indivíduos ramificados foram consideradas as ramificações abaixo de $1,30 \mathrm{~m}$, desde que tivessem DAP $\geq 5 \mathrm{~cm}$. Os indivíduos mortos, desde que mantidos eretos, foram amostrados seguindo o mesmo critério de inclusão.

Foram coletadas pelo menos três amostras dos indivíduos em estado vegetativo e seis amostras quando férteis (flor e, ou, fruto). A coleta foi realizada utilizando uma tesoura de alta poda, com $12 \mathrm{~m}$ de altura. Quando necessário, foi feita a escalada das árvores. A identificação do material botânico foi realizada através do uso de chaves analíticas e bibliografias especializadas para grupos taxonômicos, bem como através da comparação com exsicatas do Herbário do Jardim Botânico do Rio de Janeiro (RB). O materialtestemunho encontra-se depositado no Herbário do Jardim Botânico do Rio de Janeiro (RB) e no Herbário Friburguensis (FCAB), este último localizado na Pontifícia Universidade Católica do Rio de Janeiro - PUC-Rio. O sistema de classificação taxonômica adotado foi o de Cronquist (1988), com exceção da família Leguminosae, que foi considerada como família única, de acordo com Polhill et al. (1981).

A análise fitossociológica das populações foi feita empregando-se as fórmulas apresentadas por MuellerDombois e Ellenberg (1974) para densidade (DR), frequência (FR), dominância (DoRs) e valor de importância (VI). Ao mesmo tempo foram calculados os índices de diversidade de Shannon (H'), de acordo com Magurran (1988), e o índice de equabilidade (J'), de acordo com Pielou (1974).

A curva de acumulação de espécies foi realizada através do programa EstimateS versão 8.2 (COLWELL, 2009), para verificar a suficiência amostral.

Revista Árvore, Viçosa-MG, v.36, n.3, p.451-462, 2012

\section{RESULTADOS}

Na amostragem da vegetação foram coligidos 311 indivíduos (sendo 14 mortos), totalizando 92 espécies - subordinadas a 68 gêneros e 31 famílias -, das quais 12 se encontravam em morfoespécies (sete em gênero, uma em família e quatro indeterminadas). A curva de acumulação de espécies (Figura 2) não está totalmente estabilizada, apresentando curva com inclinação suave, ou seja, com incremento pequeno de espécies a cada nova parcela, aproximando-se do ponto em que não há entrada de novas espécies.

Em relação à riqueza e diversidade, este estudo (92 espécies e H’ 4,13 nats/ind) apresentou valores superiores a quase todos os trabalhos de floresta secundária em áreas de Floresta Ombrófila Densa Submontana nos Estados do Rio de Janeiro e São Paulo (Tabela 1), com exceção da floresta de Macaé de Cima (PESSOA et al., 1997), onde foram amostradas 157 espécies, porém com índice de diversidade mais baixo $(3,66)$. Esse maior número de espécies está associado ao fato de a área estudada ser de 1 ha, ou seja, quatro vezes a área amostrada neste trabalho.

O trecho estudado apresentou área basal de $34,18 \mathrm{~m}^{2} /$ ha e densidade total de 1.244 indivíduos/ ha. Esses valores estruturais estão dentro do intervalo de valores para florestas secundárias da Mata Atlântica no Estado do Rio de Janeiro. No entanto, a área basal está entre os valores mais elevados e a densidade, entre os valores mais baixos dessas florestas, como mostrado na Tabela 1 .

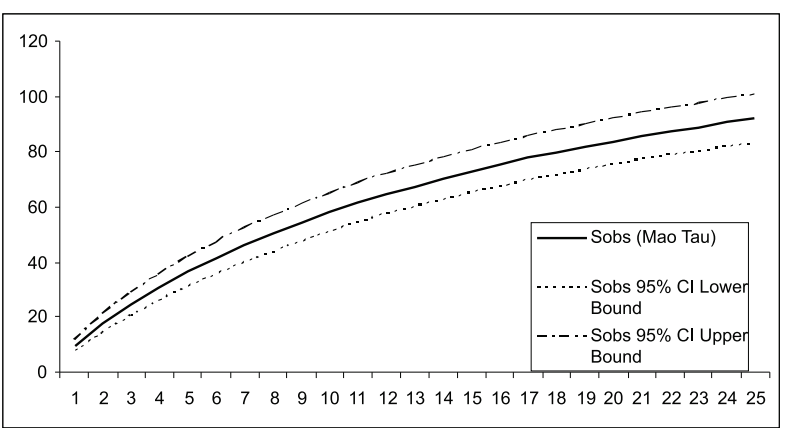

Figura 2 - Curva de acumulação de espécies das 25 parcelas da área de antiga plantação de banana no Morro da Mesa, Parque Estadual da Pedra Branca, Rio de Janeiro (RJ).

Figure 2 -Species accumulation curve for the 25 plots at the former banana plantation site at Morro da Mesa, Pedra Branca State Park, Rio de Janeiro, Brazil. 
Tabela 1 - Parâmetros estruturais e de diversidade encontrados em florestas atlânticas secundárias no Sudeste do Brasil. Alt. = altitude m.s.m.; DAP = diâmetro a 1,3 m do solo (critério de inclusão); n.d. = não disponível; Área = área amostral $\left(\mathrm{m}^{2}\right)$; ID = idade da floresta $(\operatorname{anos}) ; \mathrm{AB}=$ área basal total por área $\left(\mathrm{m}^{2} / \mathrm{ha}\right)$; DTA = densidade total por área (indivíduos/ha); $\mathrm{sp}$ = riqueza de espécies; $\left(\mathrm{H}^{\prime}\right)$ = Índice de diversidade de Shannon (nats/ind).

Table 1 - Structural and diversity parameters found in secondary forests of SE Brazil. Alt. = altitude, DAP = diameter at breast height $(D B H) ; n . d=$ not available; Área = area $(\mathrm{m} 2) ; I D=$ forest age (years); $A B=$ total basal area $(\mathrm{m} 2 /$ ha); DTA = total density (stems/ha); sp = species richness; $\left(H^{\prime}\right)=$ Shannon diversity index (nats/ind).

\begin{tabular}{|c|c|c|c|c|c|c|c|c|c|c|}
\hline Local & Alt. & Uso passado & $\mathrm{DAP}(\mathrm{cm})$ & Área $\left(\mathrm{m}^{2}\right)$ & ID & $\mathrm{AB}$ & DTA & $\mathrm{sp}$ & $\left({ }^{\prime} \mathrm{H}\right)$ & Autor \\
\hline Grumari, RJ & 140 & Banana & 5,0 & 1000 & 30 & 40,3 & 840 & 26 & 2,55 & Frietas, 2003 \\
\hline Ilha Grande, RJ & 140 & Roça caiçara & 5,0 & 2600 & 25 & 26,3 & 2784 & 70 & 3,33 & Oliveira, 2002 \\
\hline Ilha Grande, RJ & 260 & Roça caiçara & 5,0 & 2600 & 50 & 32,4 & 2273 & 63 & 3,10 & Oliveira, 2002 \\
\hline Seropédica, RJ & 30 & desconhecido & 1,0 & 4000 & 30 & 12,6 & 1482 & 23 & 1,21 & $\begin{array}{l}\text { Santos et al., } \\
1999\end{array}$ \\
\hline Macaé de Cima, RJ & 1000 & lavoura & 5,0 & 10000 & 30 & 27,9 & 2217 & 157 & 3,66 & $\begin{array}{l}\text { Pessoa et al., } \\
1997\end{array}$ \\
\hline Peruíbe, SP & 250 & n.d. & 5,0 & 2000 & 50 & 40,3 & 1420 & 63 & 3,38 & $\begin{array}{l}\text { Oliveira et al., } \\
2001\end{array}$ \\
\hline $\begin{array}{l}\text { Núcleo Santa } \\
\text { Virgínia, SP }\end{array}$ & 980 & $\begin{array}{l}\text { Corte e quiema, } \\
\text { pastagem }\end{array}$ & 3,2 & 2000 & 40 & 33,4 & 2735 & 90 & 5,27 & $\begin{array}{l}\text { Tabarelli e } \\
\text { Mantovani, } \\
1999\end{array}$ \\
\hline $\begin{array}{l}\text { Maciço da Pedra } \\
\text { Branca, RJ } \\
\text { (Guaratiba) }\end{array}$ & 100 & n.d. & 5 & 200 pontos & Secundária & 12,1 & 1558 & 45 & 2,42 & Peixoto, 2003 \\
\hline $\begin{array}{l}\text { Rio de Janeiro, Serra } \\
\text { de Inhoaíba }\end{array}$ & n.d. & $\begin{array}{l}\text { Agricultura, } \\
\text { extração } \\
\text { mineral, pasto }\end{array}$ & 5,0 & 1000 & 25 & 11,8 & 460 & 20 & 2,63 & $\begin{array}{l}\text { Santana et al., } \\
2004\end{array}$ \\
\hline $\begin{array}{l}\text { Rio de Janeiro, Serra } \\
\text { do Mendanha }\end{array}$ & n.d. & Agricultura & 5,0 & 1000 & 35 & 18,5 & 1090 & 35 & 3,10 & $\begin{array}{l}\text { Santana et al., } \\
2004\end{array}$ \\
\hline $\begin{array}{l}\text { Maciço da Pedra } \\
\text { Branca, RJ. }\end{array}$ & n.d. & $\begin{array}{l}\text { Agricultura, } \\
\text { pasto }\end{array}$ & 5,0 & 1000 & 20 & 5,8 & 700 & 7 & 0,85 & $\begin{array}{l}\text { Santana et al., } \\
2004\end{array}$ \\
\hline $\begin{array}{l}\text { Silva Jardim, RJ } \\
\text { inferior }\end{array}$ & 200 & Banana & 1,0 & 1200 & 20 & 15,1 & 1225 & 32 & 2,93 & $\begin{array}{l}\text { Borém e } \\
\text { Oliveira-Filho, } \\
2002\end{array}$ \\
\hline $\begin{array}{l}\text { Silva Jardim, RJ } \\
\text { medio }\end{array}$ & 300 & Banana & 1,0 & 1200 & 20 & 20,8 & 1475 & 66 & 3,67 & $\begin{array}{l}\text { Borém e } \\
\text { Oliveira-Filho, } \\
2002\end{array}$ \\
\hline $\begin{array}{l}\text { Silva Jardim, RJ } \\
\text { superior }\end{array}$ & 400 & n.d. & 1,0 & 1200 & 20 & 33,3 & 2125 & 83 & 3,67 & $\begin{array}{l}\text { Borém e } \\
\text { Oliveira-Filho } \\
2002\end{array}$ \\
\hline Poço das Antas, RJ & 30 & $\begin{array}{l}\text { Extração de } \\
\text { madeira }\end{array}$ & 2,5 & 2500 & 40 & 24,4 & 2716 & 104 & 3,78 & Neves, 2003 \\
\hline $\begin{array}{l}\text { Maciço da Pedra } \\
\text { Branca, RJ }\end{array}$ & 300 & Banana & 5,0 & 2500 & 50 & 34,2 & 1244 & 92 & 4,13 & Este estudo \\
\hline
\end{tabular}

A Tabela 2 apresenta a relação de espécies amostradas e respectivos parâmetros fitossociológicos. Entre aquelas com maior valor de importância (VI), destacam-se: Aiouea saligna, Tachigali paratyensis, Ficus insipida, Bathysa gymnocarpa, Chrysophyllum flexuosum, Piptadenia gonoacantha, Piper rivinoides, Hyeronima alchorneoides, Miconia cinnamomifolia e Guarea guidonia, as quais perfizeram $41,87 \%$ do total de VI do trecho amostrado. As duas primeiras espécies (Aiouea salignae Tachigali paratyensis) se destacaram das demais, enquanto no resto houve pouca diferenciação em termos de VI. Esse fato evidencia uma distribuição mais balanceada dos parâmetros ao longo das espécies. Essas mesmas espécies perfizeram $34 \%$ da densidade relativa, $52,5 \%$ da dominância relativa e $30 \%$ da frequência relativa. Essa baixa participação nos parâmetros fitossociológicos é incomum em florestas secundárias. Os valores encontrados para a área estudada 
Tabela 2 - Parâmetros fitossociológicos das espécies amostradas na área de antiga plantação de banana no Morro da Mesa, Parque Estadual da Pedra Branca, Rio de Janeiro (RJ), ordenadas pelo Valor de Importância. $\mathrm{N}=$ número de indivíduos amostrados; DRs = Densidade Relativa por espécie $(\%) ; \mathrm{ABs}=$ área basal da espécie $\left(\mathrm{m}^{2}\right)$; DoRs = Dominância Relativa por espécie (\%); FA = Frequência Absoluta (\%); FR = Frequência Relativa (\%); VI = Valor de Importância; e VC = Valor de Cobertura.

Table 2 - Phytosociological parameters of the species inventoried at the former banana plantation at Morro da Mesa, Pedra Branca State Park, Rio de Janeiro, Brazil. N= number of stems; DRs=Relative Density per species (\%); Abs= total basal area per species; DoRs= Relative Dominance per species (\%); FA=Absolute Frequency $(\%) ; F R=$ Relative Frequency (\%); VI= Importance Value; and VC=Cover Value.

\begin{tabular}{|c|c|c|c|c|c|c|c|c|}
\hline Espécie & $\mathbf{N}$ & DRs & ABs & DoRs & FA & FR & VI & $\mathbf{V C}$ \\
\hline Aiouea saligna Meisn. & 26 & 8,8 & 0,262 & 3,27 & 68 & 7,00 & 19,02 & 12,02 \\
\hline Tachigali paratyensis (Vell.) H.C. Lima & 10 & 3,4 & 0,920 & 11,47 & 36 & 3,70 & 18,54 & 14,84 \\
\hline Ficus insipida Willd. & 1 & 0,3 & 0,920 & 11,47 & 4 & 0,41 & 12,22 & 11,81 \\
\hline Bathysa gymnocarpa K. Schum & 16 & 5,4 & 0,177 & 2,21 & 32 & 3,29 & 10,89 & 7,59 \\
\hline Chrysophyllum flexuosum Mart. & 14 & 4,7 & 0,120 & 1,50 & 40 & 4,12 & 10,33 & 6,21 \\
\hline Piptadenia gonoacantha (Mart.) J.F. Macbr. & 4 & 1,3 & 0,542 & 6,76 & 16 & 1,65 & 9,75 & 8,11 \\
\hline Piper rivinoides Kunth. & 14 & 4,7 & 0,047 & 0,59 & 40 & 4,12 & 9,42 & 5,30 \\
\hline Hyeronima alchorneoides Allemão & 8 & 2,7 & 0,244 & 3,04 & 32 & 3,29 & 9,03 & 5,74 \\
\hline Miconia cinnamomifolia (DC.) Naudin & 2 & 0,7 & 0,596 & 7,43 & 8 & 0,82 & 8,93 & 8,11 \\
\hline Guarea guidonia (L.) Sleumer. & 6 & 2,0 & 0,383 & 4,78 & 16 & 1,65 & 8,44 & 6,80 \\
\hline Malouetia arborea (Vell.) Miers. & 11 & 3,7 & 0,123 & 1,53 & 24 & 2,47 & 7,71 & 5,24 \\
\hline Guapira opposita (Vell) Reitz & 9 & 3,0 & 0,070 & 0,87 & 24 & 2,47 & 6,37 & 3,90 \\
\hline Myrcia falax (Rich.) DC. & 4 & 1,3 & 0,163 & 2,03 & 16 & 1,65 & 5,03 & 3,38 \\
\hline Sparattosperma leucanthum (Vell.) Benth. & 2 & 0,7 & 0,267 & 3,33 & 8 & 0,82 & 4,83 & 4,00 \\
\hline Mollinedia longifolia Tul. & 6 & 2,0 & 0,023 & 0,29 & 24 & 2,47 & 4,78 & 2,31 \\
\hline Casearia obliqua Spreng. & 5 & 1,7 & 0,144 & 1,80 & 12 & 1,23 & 4,71 & 3,48 \\
\hline Indeterminada sp. 2 & 2 & 0,7 & 0,241 & 3,01 & 8 & 0,82 & 4,50 & 3,68 \\
\hline Guatteria glabrescens R.E. Fr. & 4 & 1,3 & 0,144 & 1,80 & 12 & 1,23 & 4,38 & 3,14 \\
\hline Aniba firmula (Nees et Mart.) Mez & 4 & 1,3 & 0,111 & 1,38 & 16 & 1,65 & 4,38 & 2,73 \\
\hline Eclinusa ramiflora Mart. & 6 & 2,0 & 0,021 & 0,26 & 20 & 2,06 & 4,34 & 2,28 \\
\hline Ocotea divaricata (Nees) $\mathrm{Mez}$ & 5 & 1,7 & 0,015 & 0,19 & 20 & 2,06 & 3,93 & 1,87 \\
\hline Nectandra membranacea (Sw.) Griseb. & 4 & 1,3 & 0,074 & 0,92 & 16 & 1,65 & 3,92 & 2,27 \\
\hline Myrocarpus frondosus Fr. Allemão & 3 & 1,0 & 0,122 & 1,52 & 12 & 1,23 & 3,77 & 2,53 \\
\hline Guarea macrophylla subsp. tuberculata (Vell.) T.D. Penn & 5 & 1,7 & 0,034 & 0,42 & 16 & 1,65 & 3,75 & 2,11 \\
\hline Miconia tristis Spring. & 5 & 1,7 & 0,019 & 0,24 & 16 & 1,65 & 3,57 & 1,92 \\
\hline Trichilia lepidota Mart. & 2 & 0,7 & 0,165 & 2,06 & 8 & 0,82 & 3,55 & 2,73 \\
\hline Indeterminada. sp. 1 & 4 & 1,3 & 0,041 & 0,51 & 16 & 1,65 & 3,50 & 1,86 \\
\hline Artocarpus heterophyllus Lam. & 2 & 0,7 & 0,157 & 1,96 & 8 & 0,82 & 3,45 & 2,63 \\
\hline Lamanonia ternata Vell. & 3 & 1,0 & 0,097 & 1,21 & 12 & 1,23 & 3,45 & 2,22 \\
\hline Casearia sylvestris $\mathrm{Sw}$ & 3 & 1,0 & 0,089 & 1,11 & 12 & 1,23 & 3,35 & 2,12 \\
\hline Machaerium incorruptibile Allemão. & 2 & 0,7 & 0,147 & 1,83 & 8 & 0,82 & 3,33 & 2,51 \\
\hline Ocotea teleiandra (Meisn.) Mez & 4 & 1,3 & 0,020 & 0,25 & 16 & 1,65 & 3,24 & 1,60 \\
\hline Inga laurina (Sw.) Willd. & 3 & 1,0 & 0,086 & 1,07 & 8 & 0,82 & 2,91 & 2,08 \\
\hline Euterpe edulis Mart. & 4 & 1,3 & 0,021 & 0,26 & 12 & 1,23 & 2,84 & 1,61 \\
\hline Lacistema serrulatum Mart. & 4 & 1,3 & 0,020 & 0,25 & 12 & 1,23 & 2,83 & 1,60 \\
\hline Cedrela odorata $\mathrm{L}$. & 3 & 1,0 & 0,068 & 0,85 & 8 & 0,82 & 2,68 & 1,86 \\
\hline Pterocarpus rohrii Vahl. & 1 & 0,3 & 0,154 & 1,92 & 4 & 0,41 & 2,67 & 2,26 \\
\hline Cordia sp. & 3 & 1,0 & 0,026 & 0,32 & 12 & 1,23 & 2,57 & 1,33 \\
\hline Lecythis lanceolata Poiret & 3 & 1,0 & 0,024 & 0,30 & 12 & 1,23 & 2,54 & 1,31 \\
\hline Pouteria glazioviana (Piure) Dub & 3 & 1,0 & 0,015 & 0,19 & 12 & 1,23 & 2,43 & 1,20 \\
\hline Tibouchina granulosa (Desr.) Cogn. & 1 & 0,3 & 0,130 & 1,62 & 4 & 0,41 & 2,37 & 1,96 \\
\hline
\end{tabular}

Revista Árvore, Viçosa-MG, v.36, n.3, p.451-462, 2012 
Tabela 2 - Cont.

Table 2 - Cont

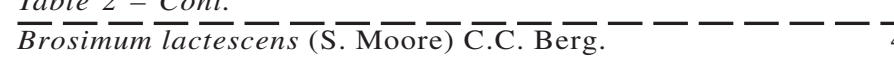
Astrocaryum aculeatissimum (Schott) Burret

Calycorectes sellowianus O. Berg.

Eugenia cuprea (O. Berg) Nied.

Protium widgrenii Engl.

Swartzia simplex var. grandiflora (Raddi) R.S. Cowan

Indeterminada sp.4

Cupania furfuracea Radlk

Ocotea elegans $\mathrm{Mez}$

Sloanea garkena K. Schum.

Tabernaemontana laeta (Mart.) Miers.

Tetrachidium rubrinervium Poepp. Et Endl.

Inga vera subsp. affinis (DC.) T.D. Penn.

Allophylus edulis (A. St. Hill.) Radlk.

Casearia sp.

Guarea kunthiana A. Juss.

Platycyamus regnelli Benth.

Licania kunthianaHook.f.

Musa sp.

Brosimum guianense Aubl.

Rubiaceae sp.

Ocotea schottii (Meisn.) Mez

Psychotria astrelantha Wernh.

Miconia calvescens DC.

Myrcia pubipetala Miq.

Cecropia glaziovi Snethlage

Anadenanthera colubrina (Vell.) Brenan

Alcchornea iricurana Casar.

Persea americana Miller

Sloanea monosperma Vellozo

Rustia formosa (Cham. \& Schltdl. ex DC.) Klotzsch

Psychotria sp.

Cariniana estrellensis (Raddi.) Kuntze

Virola oleifera (Scott) A.C.Sm

Luehea candicans Mart.

Eugenia prasina O. Berg

Endlicheria sp.

Quiina glaziovii Eng1.

Rhodostemonodaphne macrocalyx (Meisn.) Rohwer

ex Madriñán

Calycorectes sp.

Cariniana legalis (Mart.) Kuntze

Coussarea nodosa Benth. et Hook

Psychotria stenocalyx M. Arg.

Ceiba speciosa (A. St.-Hil.) Ravenna

Cryptocarya saligna $\mathrm{Mez}$

Indeterminada sp. 3

Piper arboreum Aubl.

Tovomita leucantha (Schl.) Pl. et Tr.

Cordia superba Cham.

Pera glabrata (Schott) Baill

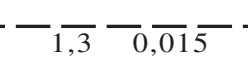

$\frac{1}{0}, \frac{1}{19}$

$0,7 \quad 0,066$

$0,7 \quad 0,049$

0,82

0,82
0,61

$\begin{array}{ll}1,0 & 0,022\end{array}$

$\begin{array}{ll}0,3 & 0,099\end{array}$

0,27

$\begin{array}{ll}1,0 & 0,007\end{array}$

$0,7 \quad 0,031$

1,23

0,09

$\begin{array}{ll}0,7 & 0,028\end{array}$

$0,3 \quad 0,084$

$\begin{array}{ll}0,7 & 0,022\end{array}$

$0,3 \quad 0,080$

$0,7 \quad 0,018$

$0,7 \quad 0,017$

$0,7 \quad 0,011$

$0,7 \quad 0,011$

$0,7 \quad 0,007$

$0,3 \quad 0,066$

$0,7 \quad 0,006$

$0,7 \quad 0,006$

$0,7 \quad 0,005$

$0,7 \quad 0,005$

$0,7 \quad 0,034$

$0,7 \quad 0,015$

$0,7 \quad 0,012$

$0,7 \quad 0,005$

$0,3 \quad 0,031$

$0,3 \quad 0,029$

$0,3 \quad 0,027$

$0,3 \quad 0,027$

$0,3 \quad 0,025$

$0,3 \quad 0,022$

$0,3 \quad 0,013$

$0,3 \quad 0,011$

$0,3 \quad 0,009$

$0,3 \quad 0,007$

$0,3 \quad 0,006$

$0,3 \quad 0,005$

$\begin{array}{llllllll}1 & 0,3 & 0,005 & 0,06 & 4 & 0,41 & 0,81 & 0,40\end{array}$

0,39

0,35

1,05

0,27

1,00

0,22

0,21

0,14

0,14

0,09

0,82

0,07

0,07

0,06

0,06

0,42

0,19

0,15

0,06

0,39

0,36

$-\frac{1}{8}$

$\overline{0}, \overline{82}-\overline{2,36}-\frac{1}{1,53}$

$0,82 \quad 2,32$

1,50

$\begin{array}{llll}8 & 0,82 & 2,11 & 1,28\end{array}$

$\begin{array}{llll}8 & 0,82 & 2,11 & 1,28 \\ 4 & 0,41 & 1,98 & 1,57\end{array}$

$8 \quad 0,82 \quad 1,92 \quad 1,10$

$\begin{array}{llll}8 & 0,82 & 1,88 & 1,06\end{array}$

$\begin{array}{llll}8 & 0,82 & 1,85 & 1,02\end{array}$

$\begin{array}{llll}4 & 0,41 & 1,80 & 1,38\end{array}$

$\begin{array}{llll}8 & 0,82 & 1,77 & 0,95\end{array}$

$\begin{array}{llll}4 & 0,41 & 1,75 & 1,33\end{array}$

$\begin{array}{llll}8 & 0,82 & 1,72 & 0,90\end{array}$

$8 \quad 0,82 \quad 1,71 \quad 0,89$

$\begin{array}{llll}8 & 0,82 & 1,63 & 0,81\end{array}$

$\begin{array}{llll}8 & 0,82 & 1,63 & 0,81\end{array}$

$\begin{array}{llll}8 & 0,82 & 1,58 & 0,76\end{array}$

$\begin{array}{llll}4 & 0,41 & 1,57 & 1,16\end{array}$

$\begin{array}{llll}8 & 0,82 & 1,57 & 0,75\end{array}$

$\begin{array}{llll}8 & 0,82 & 1,57 & 0,75\end{array}$

$\begin{array}{llll}8 & 0,82 & 1,56 & 0,74\end{array}$

$\begin{array}{llll}8 & 0,82 & 1,56 & 0,74\end{array}$

$\begin{array}{llll}4 & 0,41 & 1,51 & 1,10 \\ 4 & 0,41 & 1,27 & 0,86\end{array}$

$\begin{array}{llll}4 & 0,41 & 1,23 & 0,82 \\ 4 & 0,41 & 1,15 & 0,74\end{array}$

$\begin{array}{lllll} & 4 & 0,41 & 1,11 & 0,70\end{array}$

$\begin{array}{lllll}0,34 & 4 & 0,41 & 1,08 & 0,67\end{array}$

$\begin{array}{lllll}0,34 & 4 & 0,41 & 1,08 & 0,67\end{array}$

$\begin{array}{lllll}0,31 & 4 & 0,41 & 1,06 & 0,65\end{array}$

$\begin{array}{lllll}0,27 & 4 & 0,41 & 1,02 & 0,61\end{array}$

$\begin{array}{lllll}0,16 & 4 & 0,41 & 0,91 & 0,50\end{array}$

$\begin{array}{lllll}0,16 & 4 & 0,41 & 0,91 & 0,50 \\ 0,14 & 4 & 0,41 & 0,89 & 0,47\end{array}$

$\begin{array}{lllll}0,11 & 4 & 0,41 & 0,86 & 0,45\end{array}$

$\begin{array}{lllll}0,09 & 4 & 0,41 & 0,84 & 0,42\end{array}$

$\begin{array}{lllll}0,09 & 4 & 0,41 & 0,84 & 0,42 \\ 0,07 & 4 & 0,41 & 0,82 & 0,41\end{array}$

$\begin{array}{lllll}0,06 & 4 & 0,41 & 0,81 & 0,40\end{array}$

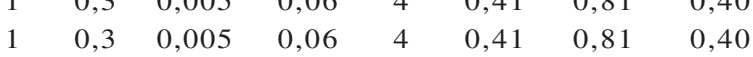

Rollinia sp.

\begin{tabular}{lllllll}
0,3 & 0,004 & 0,05 & 4 & 0,41 & 0,80 & 0,39 \\
0,3 & 0,004 & 0,05 & 4 & 0,41 & 0,80 & 0,39 \\
0,3 & 0,004 & 0,05 & 4 & 0,41 & 0,80 & 0,39 \\
0,3 & 0,004 & 0,05 & 4 & 0,41 & 0,80 & 0,39 \\
0,3 & 0,003 & 0,04 & 4 & 0,41 & 0,79 & 0,37 \\
0,3 & 0,003 & 0,04 & 4 & 0,41 & 0,79 & 0,37 \\
0,3 & 0,003 & 0,04 & 4 & 0,41 & 0,79 & 0,37 \\
0,3 & 0,003 & 0,04 & 4 & 0,41 & 0,79 & 0,37 \\
0,3 & 0,003 & 0,04 & 4 & 0,41 & 0,79 & 0,37 \\
0,3 & 0,002 & 0,02 & 4 & 0,41 & 0,77 & 0,36 \\
0,3 & 0,002 & 0,02 & 4 & 0,41 & 0,77 & 0,36 \\
0,3 & 0,002 & 0,02 & 4 & 0,41 & 0,77 & 0,36 \\
\hline & & & & & &
\end{tabular}


foram bastante inferiores aos de Oliveira (2002) para uma floresta de 50 anos, o qual encontrou para as 10 espécies mais importantes $72,1 \%$ da densidade relativa, $53,3 \%$ da frequência relativa, $82,5 \%$ da dominância relativa e $69,3 \%$ do VI.

\section{DISCUSSÃO}

O número de espécies foi relativamente elevado quando considerados o tamanho amostral da área e o estágio sucessional. Florestas secundárias podem apresentar elevado número de espécies à medida que incorporam espécies pioneiras que não estão sendo mais recrutadas e, ao mesmo tempo, outras tolerantes à sombra, típicas de estágios sucessionais mais avançados (DENSLOW, 1980).

Devido ao fato de a curva de acumulação de espécies não estar totalmente estabilizada, especulou-se a necessidade de aumentar o número de unidades amostrais. Porém, esse aumento foi impossibilitado pela limitação da área com efetivo uso de plantação de banana no passado. Ao mesmo tempo, em razão da heterogeneidade da floresta Atlântica com mosaicos de diferentes idades e apresentando variação nos condicionamentos hidrológicos e edáficos, bem como uma conhecida relação entre área e riqueza florística (ROSENZWEIG, 1995), a entrada de novas espécies dificilmente poderia ser estabilizada dentro de uma amostragem executável em escala espacial e temporal adequada.

O índice de diversidade de Shannon relativo a este trabalho está próximo do valor encontrado em dois trechos de florestas em bom estado de conservação, em Macaé de Cima (4,05) e na Ilha Grande (4,28) (GUEDESBRUNI et al., 1997; OLIVEIRA, 2002). Guedes-Bruni (1998), em estudo de similaridade florística entre seis trechos de Mata Atlântica, concluiu que existe gradativa substituição de espécies num gradiente altitudinal no sentido serra-baixada. Ao mesmo tempo, o alto valor de equabilidade ( $\mathbf{J}$ ') encontrado $(0,91)$ indica que não há o domínio na comunidade de pequeno grupo de espécies, contribuindo com o elevado valor do índice de diversidade.

Pode-se remeter a alta diversidade de espécies à hipótese de distúrbio intermediário (CONNEL, 1978; DENSLOW, 1980; MOLINO; SABATIER, 2001), a qual preconiza que é encontrada maior diversidade de espécies em níveis intermediários de distúrbio, quando maior número de espécies pode coexistir e, dessa forma, é evitada a exclusão competitiva devido à repartição de nichos em clareiras de tamanhos variáveis. No caso deste estudo, a plantação de banana pode ser considerada um distúrbio intermediário, pois embora grande parte da cobertura vegetal seja eliminada para a implantação desse cultivo, todavia ela mantém boa condição edáfica e heterogeneidade luminosa. Assim, a regeneração de uma plantação abandonada é acelerada devido a esses fatores ambientais favoráveis, contando que esteja próximo de uma fonte de propágulos, como é o caso da área estudada.

Em relação aos parâmetros estruturais, o valore de densidade deste trabalho é comparável aos de outras florestas secundárias de Mata Atlântica (Tabela 1). No entanto, o valor de área basal está um pouco acima do observado em alguns trabalhos comparados no Rio de Janeiro (PESSOA et al., 1997; SANTOS et al., 1999; SANTANA et al., 2004; PEIXOTO, 2003; NEVES, 2003) (Tabela 1). Esse resultado pode estar sendo influenciado pela presença de algumas árvores remanescentes, como Ficus insipida Willd. e também por alguns indivíduos de espécies pioneiras e secundárias iniciais, que estão com porte bastante elevado (Tibouchina granulosa (Desr.) Cogn., Miconiacinnamomifolia (DC.) Naudin, Tachigali paratyensis (Vell.) H.C. Lima, Sparattosperma leucanthaum (Vell.) Benth. e Piptadenia gonoacantha (Mart.) J.F. Macbr.). Outros estudos, como o de Freitas (2003), em 0,1 ha de uma floresta de 30 anos, encontraram uma área basal relativamente elevada (40,3 m²/ha), o que está associado ao fato de a amostragem ter incluído algumas árvores remanescentes (como Ficus gomelleira Kunth). Guevara et al. (1986) apontaram que árvores remanescentes são importantes para a sucessão ecológica, à medida que provêm um núcleo de proteção e alimento para animais de fragmentos próximos. Ainda é destacado o papel da avifauna na dispersão de frutos sob a copa dessas árvores remanescentes, além de criar ambiente favorável para o estabelecimento de plantas (CARRIÈRE et al., 2002). Portanto, tanto neste estudo quanto no estudo supracitado, as árvores remanescentes que os agricultores pouparam podem ter facilitado a subsequente sucessão secundária.

Neste trabalho, Ficus insipida foi amostrada com apenas um indivíduo de grande porte $(\mathrm{DAP}=108 \mathrm{~cm})$. Esse padrão é comum em muitos estudos já realizados, 
em que árvores remanescentes persistem, seja por motivos culturais das populações que habitam, ou habitavam, as áreas estudadas, seja pela dificuldade em remover tais árvores para a implantação de roças e plantações. Em área de plantação de banana abandonada no Maciço da Pedra Branca, Freitas (2003) também encontrou Ficus gomeleira entre as espécies com maior importância, representada por um indivíduo amostrado. Guedes-Bruni (1998) achou essa mesma espécie igualmente destacada entre os táxons mais importantes na estrutura da Estação Ecológica Estadual de Paraíso (RJ), representada por apenas um indivíduo. Esses estudos também evidenciaram o papel cultural das populações locais na preservação desses espécimes em plenas florestas secundárias. Esse processo de seleção de algumas espécies de grande porte, e em alguns casos de grande longevidade, pode influenciar a dinâmica sucessional da floresta. Foi constatado que existe uma cultura popular que poupa do abate árvores de porte muito elevado (DAP> $1 \mathrm{~m}$ ), que, segundo Seu Amaro Bastos Soares (informante local), eram mantidas para "deixar para a terra" devido ao seu porte e por uma noção de respeito à natureza. O gênero Ficus, por sua vez, apresenta forte aspecto religioso-cultural devido à sua citação na Bíblia (FONSECA, 2005). Esse aspecto religioso levou a um processo de preservação seletiva de indivíduos de grande porte desse gênero, por populações tradicionais que habitam a Mata Atlântica (Rogério Ribeiro de Oliveira - comunicação pessoal). Portanto, essas motivações religiosas também têm importância no processo de seleção de algumas espécies, afetando a dinâmica regenerativa da comunidade.

As duas espécies mais importantes deste estudo, Aiouea saligna (Lauraceae) e Tachigali paratyensis (Leguminosae), se destacaram na comunidade a partir de diferentes parâmetros. Aiouea saligna caracterizou-se como espécie secundária inicial e que apresentou a maior população no trecho estudado (26 ind.), além de distribuição ampla nas parcelas (68\%). Já Tachigali paratyensis apresentou grande participação na dominância da comunidade $(11,47)$. Se se considerarem as espécies a partir do valor de cobertura, esta espécie seria a de maior destaque. T. paratyensis encontra condições ideais para germinação e estabelecimento em locais com umidade elevada (SILVA; LIMA, 2007). Possivelmente a localização da floresta na vertente sul, associada à boa drenagem dos solos de plantação de banana, tenha facilitado o estabelecimento dessa espécie.
As espécies Bathysa gymnocarpa e Chrysophyllum fleuxuosum destacaram-se, principalmente por apresentar densidades intermediárias (16 e 14 ind.). Essas duas espécies exibiram indivíduos com pequeno porte, compondo o estrato arbóreo inferior da comunidade. Ambas as espécies apresentaram elevada concentração de indivíduos na primeira classe de diâmetro $(5-10 \mathrm{~cm})$. Kurtz e Araújo (2000) encontraram C. flexuosum como quarta espécie em VI em uma floresta conservada em Cachoeiras de Macacu (RJ), sendo mencionada como uma das mais importantes da Mata Atlântica. Esses autores destacaram C. flexuosum como uma espécie secundária tardia/climáxica, tendo vasta regeneração no interior da mata (KURTZ; ARAÚJO, 2000). GuedesBruni (1998), na Estação Estadual Ecológica de Paraíso $(\mathrm{RJ})$, encontrou esse mesmo táxon entre as espécies com maiores valores de importância.

Outra espécie relevante foi Piptadenia gonoacatnha, que apresentou valores relativos de densidade e frequência baixos $(1,3$ e 1,67), tendo, no entanto, forte participação na dominância $(6,76)$, por se tratar de espécie pioneira que se encontra em uma floresta em grau intermediário de sucessão. Borém e Oliveira-Filho (2002) observaram num trecho de floresta secundária, em área de uso pretérito para plantação de banana e posteriormente abandonada, a espécie $P$. gonoacantha com expressivo valor de importância, embora com apenas quatro indivíduos. Santana et al. (2004) também encontraram alto valor de importância dessa espécie em duas áreas estudadas de floresta secundária no Maciço do Mendanha e Maciço da Pedra Branca, Rio de Janeiro (RJ). Outros estudos destacaram esse táxon por seu elevado VI e por sua frequência em áreas degradadas e sujeitas ao efeito de borda (FERREIRA et al., 1999; FREITAS, 2003; SOUZA et al., 2003).

A presença de Euterpe edulis Mart., juntamente com Virola oleifera (Scott) A.C.Sm- espécies consideradas indicadoras para as formações submontanas e de bom estado de conservação (GUEDESBRUNI et al., 1997; OLIVEIRA, 2002) - além de outras espécies climáxicas, como Cariniana legalis (Mart.) Kuntze, Cariniana estrelensis (Raddi.) Kuntze, Ocotea spp., entre outras, pode indicar que a floresta estudada encontra-se progredindo para um estágio de sucessão mais avançado. Duas espécies frutíferas exóticas foram amostradas: Artocarpus heterophyllus Lam. e Persea americana Miller e constituem testemunho do uso pretérito exercido pelas populações ali estabelecidas. 
Acrescente-se ainda, como testemunho do uso pretérito de cultivo, a presença de dois indivíduos de bananeira (Musa sp.), que, embora não seja uma espécie arbustivoarbórea, foi incluída na amostragem para documentar remanescentes de espécies dominantes no passado.

A presença de espécies secundárias iniciais e tardias, bem como o enriquecimento por espécies pioneiras, torna evidente um processo de dinâmica sucessional, o qual pode ser justificado não só pela proximidade deste trecho alterado da área core da floresta, mas também pela ausência de novas atividades antrópicas no local. A proximidade do trecho estudado com áreas mais preservadas (devido à distância dos habitantes e ao difícil acesso) permite rápida recolonização por propágulos dessas áreas. A decadência da região do Camorim como produtora de banana, bem como a efetiva criação do Parque Estadual da Pedra Branca em 1974, permitiu a recuperação da floresta sem a reincidência de novas atividades agrícolas.

\section{CONCLUSÃO}

A paisagem que compõe o Maciço da Pedra Branca é composta por uma história ambiental bastante diversificada, em que múltiplos episódios alteraram seus atributos de estrutura, composição e funcionalidade. $\mathrm{Na}$ área estudada, esta história ambiental está registrada não só nos documentos históricos, mas embutida na cultura da população local, que em parte se reflete nos vestígios físicos na floresta. Esses vestígios podem estar representados não apenas por marcas de antigas construções, muros e plantações, mas, ainda, por vestígios na estrutura e composição da floresta.

Os usos passados pelos quais as florestas foram submetidas deixaram marcas específicas, pois esses usos variam de natureza, intensidade e frequência. A área estudada teve como último uso uma plantação de banana, embora outros usos devam ter ocorrido em função de suas características topográficas. As particularidades dessa cultura influenciaram a sucessão ecológica que ocorreu após o seu abandono. Um cultivo de banana artesanal sofre manejo atenuado, ocorrendo a limpeza do material residual uma vez por ano e a poda dos indivíduos que já produziram cacho. Esse processo favoreceu a condição de maior sombreamento para a referida área. Essas características afetaram a regeneração da vegetação, pois a quantidade de luz é fator essencial para o estabelecimento de espécies. Dessa forma, as

Revista Árvore, Viçosa-MG, v.36, n.3, p.451-462, 2012 espécies amostradas neste estudo refletiram o uso do solo passado e a cultura local. O cultivo da banana, após seu abandono, permitiu a entrada de espécies com estratégias de estabelecimento e propagação em condições de pouca luminosidade. Ao mesmo tempo, a presença de uma figueira de diâmetro elevado remete aos mitos da cultura popular, que acabou influenciando a estrutura da comunidade biológica. Essas práticas socioeconômicas religioso-culturais transformam a paisagem, onde a floresta passa a fazer parte da cultura local, gerando mitos e usos diversos, tanto quanto a floresta interfere nas populações humanas circunvizinhas a ela.

Esse conjunto de intervenções feito ao longo do tempo por diversos agentes e processos contribui para que a paisagem da Mata Atlântica assuma caráter de grande diversidade, em que elementos naturais e antrópicos se misturam, formando um complexo mosaico. Assim, a visão integradora entre as práticas humanas pretéritas e a situação atual das florestas permite aos pesquisadores, especialmente aqueles de países megadiversos, tanto biológicos quanto culturais, projetarem ações que assegurem a conservação das florestas tropicais e seus valores culturais.

\section{AGRADECIMENTOS}

À Fundação de Amparo à Pesquisa do Estado do Rio de Janeiro (FAPERJ), pela bolsa de estudos concedida ao primeiro autor; à Escola Nacional de Botânica Tropical do Jardim Botânico do Rio de Janeiro, pelo apoio e pela infraestrutura; à Direção do Parque Estadual da Pedra Branca; ao informante local, por seu conhecimento e experiência, sem a qual o trabalho não teria tido o sucesso que teve; ao grupo de pesquisadores/taxonomistas do Instituto de Pesquisa Jardim Botânico do Rio de Janeiro; e aos revisores anônimos da revista.

\section{REFERÊNCIAS}

BORÉM, R. A. T.; OLIVEIRA-FILHO, A. T. Fitossociologia do estrato arbóreo em uma topossequiência alterada de Mata Atlântica, no Município de Silva Jardim-RJ, Brasil. Revista Árvore, v.26, n.6, p.727-742, 2002.

BROWN, S.; LUGO, A. E. Tropical secondary forests. Journal of Tropical Ecology, v.6, n.1, p.1-32, 1990. 
CARRIÈRE, S. M.; LETOURMY, P.; MCKEY, D. B. Effects of remnant trees in fallows on diversity and structure of forest regrowth in a slash-and-burn agricultural system in southern Cameroon. Journal of Tropical Ecology, v.18, p.375-396, 2002.

COLWELL, R. K. EstimateS: statistical estimation of species richness and shared species from samples. Version 8.2. 2009. User's guide and application published at: http://purl.oclc.org/ estimates.

CONNELL, J. H. Diversity in tropical rain forests and coral reefs. Science, v.1999, p.1302-1310, 1978

CONSERVATION INTERNATIONAL DO BRASIL. Avaliação e ações prioritárias para a conservação da biodiversidade da Mata Atlântica e Campos Sulinos. Brasília: MMA/SBF, 2000.

CRONQUIST, A. The evolution and classification of flowering plants. New York: The New York Botanical Garden, 1988.

DENSLOW, J. S. Patterns of plant species diversity during succession under different disturbance regimes. Oecologia, v.46, n.1, p.18-21, 1980.

FERREIRA R. L. C.; SOUZA, A. L; SILVA, G. F. Dinâmica da estrutura de uma floresta secundária de transição. III. Estrutura Horizontal. Revista Árvore, v.23, n.2, p.157-168, 1999.

FONSECA, D. P. R. A marca do sagrado. In: OLIVEIRA, R.R. (org.). As marcas do homem na floresta: História ambiental de um trecho urbano de Mata Atlântica. Rio de Janeiro: PUC-Rio, 2005. p.11-22.

FREITAS, M. M. Funcionalidade hidrológica dos cultivos de banana e territorialidade na paisagem do Parque Municipal de Grumari Maciço da Pedra Branca - RJ. 2003. Tese (Doutorado em Geografia) -Universidade Federal do Rio de Janeiro, Rio de Janeiro, 2003.

\section{FUNDAÇÃO INSTITUTO BRASILEIRO DE} GEOGRAFIA E ESTATÍSTICA - IBGE. Manual técnico da vegetação brasileira. Rio de Janeiro: IBGE, 1992. 92p.
GALVÃO, M. C. Lavradores brasileiros e portugueses na Vargem Grande. Boletim Carioca de Geografia - AGB, v.10, n.3-4, p.36-60, 1957.

GUARIGUATA, M. R.; OSTERTAG, R. Sucesíon secundaria. In: GUARIGUATA, M.R.; CATAN, H. (Eds.). Ecología y conservacíon de bosques neotropicales. San José: Libro Universitario Regional, 2002. p.591-623.

GUEDES-BRUNI, R. R. Composição, estrutura e similaridade florística de dossel em seis unidades fisionômicas de Mata Atlântica no Rio de Janeiro. 1998. Tese (Doutorado em Ecologia) Universidade de São Paulo, São Paulo, 1988.

GUEDES-BRUNI, R. R.; PESSOA, S. V. A.; KURTZ, B. C. Composição florística e estrutura do componente arbustivo-arbóreo de um trecho preservado de floresta montana na Reserva Ecológica de Macaé de Cima. In: LIMA, H. C.; GUEDES-BRUNi, R. R. (Eds.) Serra de Macaé de Cima: diversidade florística e conservação em Mata Atlântica. Rio de Janeiro: Instituto de Pesquisas Jardim Botânico do Rio de Janeiro, 1997. p.127-145.

GUEVARA, S.; PURATA, S. E.; van der MAAREL, E. The role of remnant forest trees in tropical secondary succession. Vegetatio, v.66, p.77-84, 1986.

KURTZ, B. C.; ARAÚJO, D. S. D. Composição florística e estrutura do componente arbóreo de um trecho de Mata Atlântica na Estação Ecológica Estadual do Paraíso, Cachoeiras de Macacu, Rio de Janeiro, Brasil. Rodriguésia, v.51, p.69-112, 2000.

MAGURRAN, A. E. Ecological diversity and its measurement. London: Croom Helm, 1988.

MOLINO, J. F.; SABATIER, D. Tree diversity in tropical rain forest: a validation of the intermediate disturbance hypothesis. Science, v.294, n.5547, p.1702-1704. 2001.

MUELLER-DOMBOIS, D.; ELLENBERG, H. Aims and methods of vegetation ecology. New York: John Willey \& Sons, 1974.

Revista Árvore, Viçosa-MG, v.36, n.3, p.451-462, 2012 
NEVES, G. M. S. Florística e estrutura da comunidade arbustivo-arbórea em dois remanescentes de Floresta Atlântica secundária - Reserva Biológica de Poço das Antas, Silva Jardim, RJ. Dissertação (Mestrado em Botânica) - Museu Nacional, Universidade Federal do Rio de Janeiro, Rio de Janeiro, 2003.

NOGUEIRA, A. A. Vargem Grande (alguns aspectos geográficos). Boletim Carioca de Geografia - AGB, v.9, n.1-2, p.49-71, 1956.

OLIVEIRA, R. R. Ação antrópica e resultantes sobre a estrutura e composição da Mata Atlântica na Ilha Grande, RJ. Rodriguésia, v.53, n.82, p.33-58, 2002.

PEIXOTO, G. L. Florística e fitossociologia de um fragmento de Floresta Atlântica, na Serra da Capoeira Grande, Guaratiba, Rio de Janeiro. 2003. 73f. Dissertação (Mestrado em Ciências Ambientais e Florestais) - Universidade Federal Rural do Rio de Janeiro, Rio de Janeiro, 2003.

PESSOA, S. V.A.; GUEDES-BRUNI, R. R.; KURTZ, B. C. Composição florística e estrutura do componente arbustivo-arbóreo de um trecho secundário de floresta montana na Reserva Ecológica de Macaé de Cima. In: LIMA, H. C.; GUEDES-BRUNI, R. R. (Eds.) Serra de Macaé de Cima: diversidade florística e conservação em Mata Atlântica. Rio de Janeiro: Instituto de Pesquisas Jardim Botânico do Rio de Janeiro, 1997. p.147-167.

PIElou, E. C. Population and community ecology. New York: Gordon and Breach, 1974.

POLHILL, R. M.; RAVEN, P. H. \& STIRTON, C. H. Evolution and systematics of the Fabaceae. In: POLHILL, R. M.; RAVEN, P. H. (Eds). Advances in legume systematics. London: Royal Botanic Gardens, 1981. v.1.p.1-26.
ROSENZWEIG, M. L. Species diversity in space and time. Cambridge: Cambridge University Press, 1995.

SANTANA, C. A. A.; LIMA, C. C. D.; MAGALHÃES, L. M. S. Estrutura horizontal e composição florística de três fragmentos secundários na cidade do Rio de Janeiro. Acta Scientiarum. Biological Sciences, v.26, n.4, p.443-451, 2004.

SANTOS, L. A. F.; LIMA, J. P. C.; MELLO-FILHO, J. A. Corredor ecológico de regeneração natural na Floresta Nacional "Mário Xavier", em Seropédica, RJ. Floresta e Ambiente, v.6, n.1, p.106-117, 1999.

RIO DE JANEIRO. Secretaria Municipal de Meio Ambiente. Elaboração dos Projetos Executivos de Revegetação e Medidas Complementares da Bacia dos Lagos Costeiras (Baixada de Jacarepaguá) - $4^{\circ}$ Relatório Parcial. Rio de Janeiro: SMAC - Prefeitura do Rio, Fundação de Apoio à Pesquisa Científica e Tecnológica da UFRRJ/Universidade Federal Rural do Rio de Janeiro. 2000.

SILVA, L. F. G.; LIMA, H. C. Mudanças nomenclaturais no gênero Tachigali aubl. (Leguminosae - Caesalpinioideae) no Brasil. Rodriguésia, v.58, n.2, p.397-401, 2007.

SOS MATA ATLÂNTICA. 2002. Disponível em $<$ http://www.sosmatatlantica.org.br>. Acesso em: $10 / 06 / 2004$.

SOUZA, J. S. et al. Análise das variações florísticas e estruturais da comunidade arbórea de um fragmento de floresta semidecídua às margens do Rio Capivari, Lavras-MG. Revista Árvore, v.27, n.2, p.185-206, 2003.

TABARELLI, M.; MANTOVANI, W. A regeneração de uma floresta tropical Montana após corte e queima (São Paulo-Brasil). Revista Brasileira de Biologia, v.59, n.2, p.239-250, 1999. 